\title{
Higher concentrations of osteoprotegerin in type 1 diabetic patients are related to retinopathy: Results from the Poznań Prospective Study
}

\author{
Agata Grzelka ${ }^{1, A-F}$, Dariusz Naskręt1, A-F , Aleksandra Araszkiewicz ${ }^{1, A, C, E, F}$, Aleksandra Uruskaa ${ }^{1, B, C, E, F}$, \\ Małgorzata Wegner ${ }^{2, B, C, E, F}$, Dorota Zozulińska-Ziółkiewicz' ${ }^{1, A, C, E, F}$ \\ ${ }^{1}$ Department of Internal Medicine and Diabetology, Poznan University of Medical Sciences, Poland \\ ${ }^{2}$ Lipid Metabolism Laboratory, Department of General Chemistry, Chemistry and Clinical Biochemistry, Poznan University of Medical Sciences, Poland \\ A - research concept and design; B - collection and/or assembly of data; C - data analysis and interpretation; \\ $D$ - writing the article; $E$ - critical revision of the article; $F$ - final approval of the article
}

\section{Address for correspondence \\ Agata Grzelka \\ Email: agata.grzelka@gmail.com \\ Funding sources \\ The study was supported by a Polish Ministry \\ of Science and Higher Education project \\ (IP2011000771).}

Conflict of interest

None declared

Received on February 18, 2016

Reviewed on May 31, 2016

Accepted on September 6, 2016

\begin{abstract}
Background. Osteoprotegerin (OPG) is an arterial calcification marker which has been associated with vascular damage. Elevated OPG concentrations associated with low-grade inflammatory processes are found in diabetic subjects.

Objectives. The aim of the study was to assess concentrations of OPG in relation to the presence of diabetic complications in patients with diabetes type 1 (DM 1) participating in the Poznań Prospective Study (PoProStu).

Material and methods. The study included 74 patients with DM1 (48 men) with a median age of 39 years (interquartile range [IQR]: 34-43) and a median 15-year history (IQR: 14-16) of diabetes, who were participants in the PoProStu. Serum OPG concentration was measured using the ELISA method, and serum concentration of (-reactive protein was measured with a high sensitivity test (hsCRP). The visceral adipose index (VAI) was used to determine indirect markers of insulin resistance (IR). The prevalence of microangiopathic diabetes complications was assessed.
\end{abstract}

Results. Retinopathy was diagnosed in 28 patients (38\%), diabetic kidney disease (DKD) in 28 (38\%) patients, and neuropathy in 17 (23\%) patients. The median OPG level was 43.8 (28.0-74.0) pg/mL. Patients with retinopathy had higher levels of OPG than those without retinopathy: 47.5 (35.0-88.0) vs $35.4(24.7-69.4) \mathrm{pg} / \mathrm{mL}(p=0.04)$. Positive correlations were observed between OPG concentration and hsCRP ( $R s=0.53 ; p<0.001)$, HbA1c level ( $R s=0.36 ; p=0.002)$, VAl $(R s=0.23 ; p=0.04)$ and waist circumference $(\mathrm{Rs}=0.24 ; \mathrm{p}=0.04)$.

Conclusions. Higher concentrations of osteoprotegerin in DM1 patients are related to the presence of retinopathy. The study results indicate that OPG might play a role in the pathogenesis of vascular complications in association with hyperglycemia and low-grade inflammatory processes.

Key words: inflammation, hyperglycemia, osteoprotegerin, diabetic angiopathies, diabetes mellitus type 1

DOI

10.17219/acem/65072

Copyright

Copyright by Author(s)

This is an article distributed under the terms of the

Creative Commons Attribution Non-Commercial License

(http://creativecommons.org/licenses/by-nc-nd/4.0/) 
Osteoprotegerin (OPG) is a glycoprotein originally described as an inhibitor of bone resorption. ${ }^{1}$ It is a member of the tumor necrosis factor receptor superfamily, and it binds to receptor activator of nuclear factor $\mathrm{\kappa} B$ ligand (RANKL) and TNF-related apoptosis-inducing ligand (TRAIL). The effects of OPG prevent RANK-mediated kappa $B$ activation, thus influencing bone metabolism and immune responses, and inhibiting TRAIL-related apoptosis. ${ }^{2}$ Studies have linked higher levels of OPG with cardiovascular disease (CVD) and arterial calcification. ${ }^{3}$ OPG has been well described as a biomarker for endothelial dysfunction and a predictor of CVD in the general population, in obese subjects and in type 2 diabetic (DM 2) patients. ${ }^{4-6}$ Chronic diabetes complications are still a significant cause of morbidity and mortality in DM 1 patients. ${ }^{7}$ There is good evidence that hyperglycemia and low-grade inflammatory processes play an important role in the pathogenesis of the vascular complications of diabetes. ${ }^{8}$ Recent large studies have also reported OPG as an independent predictor of cardiovascular complications in a large cohort of patients with DM $1 .^{9}$

Knowledge of the potential role of OPG in diabetic microangiopathy is limited. Knudsen et al. found increased levels of OPG in the plasma of DM 2 patients with albuminuria. ${ }^{10}$ Higher plasma OPG concentrations were also observed in subjects with peripheral neuropathy in a study by Nybo et al. ${ }^{11}$ However, this association was statistically significant only in patients with DM 2. Therefore, it would be valuable to determine whether serum OPG level is related to microangiopthy in DM 1 subjects. Potentially, OPG could be a biomarker to identify patients with diabetes and microvascular complications.

The aim of this study was to assess the concentrations of OPG in DM 1 patients participating in the Poznań Prospective Study in relation to the presence of microangiopathy.

\section{Material and methods}

\section{Study design}

The Poznań Prospective Study (PoProStu) is a prospective observational study of patients with DM1 uniformly treated with intensive functional insulin therapy (IFIT) from the onset of the disease. The PoProStu enrolled 100 consecutive patients with newly diagnosed DM 1, aged below 35 years, hospitalized due to diabetic ketoacidosis at the Department of Internal Medicine and Diabetology at the Poznan University of Medical Sciences (Poland) from 1994 to 1999 , as described by Grzelka et al. ${ }^{12}$ From the onset of the disease, all the patients have been treated with IFIT, defined as a treatment method requiring multiple insulin injections during the day, counting carbohydrate equivalents, and considering upcoming physical activity. Annual follow-ups were conducted. Of the original cohort, 26 pa- tients were lost to follow-up; consequently, 74 cases were examined. The data presented in this paper - anthropometric measurements, laboratory results, and microangiopathic complication status - was derived from follow-ups conducted from October to December 2012. The 74 DM 1 patients included in this cross-sectional analysis comprised 26 women and 48 men, with a median age of 39 years (interquartile range [IQR]: $34-43$ years) and a median 15-year (IQR: 14-16) history of diabetes. All the subjects were informed of the aim of the study and gave their consent. The study was approved by the local Ethics Committee. The study is registered in the ClinicalTrials.gov database (NCT01411033). Table 1 shows the relevant clinical and demographic characteristics of the group.

Table 1. Clinical characteristics of the study group

\begin{tabular}{|c|c|}
\hline Characteristic & Study group \\
\hline No. of patients & 74 \\
\hline $\operatorname{Sex}(M / F)$ & $48 / 26$ \\
\hline Age (years) & $39(34-43)$ \\
\hline Disease duration (years) & $15(14-16)$ \\
\hline Smoking n (\%) & $22(30)$ \\
\hline Hypertension n (\%) & $29(39)$ \\
\hline $\mathrm{SBP}(\mathrm{mm} \mathrm{Hg})$ & $131(120-142)$ \\
\hline $\mathrm{DBP}(\mathrm{mm} \mathrm{Hg})$ & $83(77-90)$ \\
\hline $\mathrm{BMI}\left(\mathrm{kg} / \mathrm{m}^{2}\right)$ & $24.7(22.5-27.7)$ \\
\hline Waist circumference (cm) & $87.3(82.5-96.0)$ \\
\hline WHR & $0.86(0.82-0.93)$ \\
\hline Daily insulin dose (U/kg/d) & $45.5(36.0-52.0)$ \\
\hline VAl & $1.86(1.50-2.90)$ \\
\hline $\mathrm{HbA1c}(\%)$ & $7.7(7.1-8.7)$ \\
\hline Total cholesterol (mmol/L) & $5.2(4.5-5.8)$ \\
\hline LDL cholesterol (mmol/L) & $3.1(2.3-3.8)$ \\
\hline HDL cholesterol (mmol/L) & $1.7(1.4-2.0)$ \\
\hline Triglicerydes (mmol/L) & $0.97(0.7-1.3)$ \\
\hline $\mathrm{eGFR}\left(\mathrm{mL} / \mathrm{min} / 1,73 \mathrm{~m}^{2}\right)$ & $90.9(85.1-109.6)$ \\
\hline hsCRP (mg/L) & $1.12(0.62-2.70)$ \\
\hline Retinopathy n (\%) & $28(38)$ \\
\hline Diabetic kidney disease n (\%) & $28(38)$ \\
\hline Neuropathy n (\%) & $17(23)$ \\
\hline Any microangiopathy n (\%) & $38(51)$ \\
\hline Macroangiopathy n (\%) & $3(4)$ \\
\hline
\end{tabular}

Data shown as median (IQR); n (\%) - number (\%) of patients; SBP - systolic blood pressure; DBP - diastolic blood pressure; BMI - body mass index; WHR - waist-to-hip ratio; eGDR - estimated glucose disposal rate; VAI - visceral adipose index; LDL - low-density lipoprotein; HDL - high-density lipoprotein; eGFR - estimated glomerular filtration rate; hsCRP - high sensivity C-reactive protein.

\section{Data collection procedures}

All the patients underwent a complete physical examination with anthropometric measurements and a blood pressure check. Blood pressure was measured twice 
by the Korotkov method in a sitting position, after $10 \mathrm{~min}$ at rest, using a mercury manometer. Arterial hypertension was diagnosed if the mean blood pressure was more than $140 / 90 \mathrm{~mm} \mathrm{Hg}$ or if the patient had had arterial hypertension diagnosed previously and had received appropriate treatment. Body mass index (BMI) was calculated from the following equation: BMI = weight $(\mathrm{kg}) /$ squared height $\left(\mathrm{m}^{2}\right)$. Visceral adiposity index (VAI) was assessed using the following formula: for women VAI = [waist circumference/36.58 + (1.89 × BMI $)] \times(\mathrm{TG} / 0.81) \times(1.52 / \mathrm{HDL})$ for men VAI $=[$ waist circumference $/ 39.68+(1.88 \times \mathrm{BMI})$ ] $\times(\mathrm{TG} / 1.03) \times(1.31 / \mathrm{HDL})$.

Blood samples were collected in a fasting state. Glycated hemoglobin (HbA1c) was measured using high performance liquid chromatography with the VARIANT Haemoglobin A1c Program (Bio-Rad Laboratories, Hercules, USA). Serum C-reactive protein (hsCRP) concentration was assessed by highly sensitive microparticle enzyme turbidimetric immunoassay. Plasma glucose was measured using the hexokinase-mediated reaction. Total cholesterol, high density lipoprotein (HDL) cholesterol, low density lipoprotein (LDL) cholesterol, and triglyceride levels were determined using commercially available assay kits (F. Hoffman-LaRoche AG, Basel, Switzerland). Creatinine levels were measured using the kinetic method. The estimated glomerular filtration rate (eGFR) was calculated using the Modification of Diet in Renal Disease Study formula.

OPG levels were measured using enzyme linked immunosorbent assay kits (eBioscience Human Osteoprotegerin Instant ELISA, Thermo Fisher Scientific, Waltham, USA). OPG presenting in the serum was bound by antibody precoated on the wells. Captured protein was detected by adding a biotinylated antibody followed by streptavidin-horseradish peroxidase (SA-HRP). A substrate of SAHRP-3,3,5,5'tetramethylbenzidine (TMB) was then added to the wells. The intensity of the color was measured spectrophotometrically at $450 \mathrm{~nm}$, using a Zenyth 200 Microplate Reader (Thistle Scientific, Glasgow, UK), and the concentration of OPG was read off from a standard curve. The detection limit was $2.5 \mathrm{pg} / \mathrm{mL}$, the intra-assay coefficient of variation (CV) was $7 \%$, and the inter-assay CV was $8 \%$.

\section{Microangiopathic complications at follow-up}

Diabetic retinopathy was diagnosed using direct ophthalmoscopy through dilated pupils, followed by fundus photography in all the patients. The fundus examinations were performed using an indirect Volk lens (Volk Optical, Inc., Mentor, USA). Two fundus photographs of each eye were taken with a $45^{\circ}$ digital camera (VISUCAM, Zeiss AG, Oberkochen, Germany), 1 centered on the fovea and 1 centered on the optic disc. The evaluations of both photographs were performed by the same ophthalmologist experienced in diabetic retinopathy. Diabetic retinopathy was graded according to the classification of the American Academy of Ophthalmology: no retinopathy or mild nonproliferative retinopathy; moderate nonproliferative retinopathy; severe nonproliferative retinopathy; and proliferative retinopathy. ${ }^{13}$ The severity of retinopathy was recognized based on the presence of microaneurysms, retinal hemorrhages and hard exudates. Nonproliferative retinopathy is differentiated based on the presence of retinal bleeding, venous beading, cotton-wool spots or intraretinal microvascular anomalies.

Diabetic kidney disease (DKD) was detected at the stage of albuminuria. Urinary albumin excretion was assessed in a $12 \mathrm{~h}$ collection and recalculated for $24 \mathrm{~h}$. Albuminuria was defined as an urinary albumin excretion rate between 30 and $300 \mathrm{mg} / 24 \mathrm{~h}$ in 2 out of 3 samples collected over a 3-month period, after the exclusion of secondary causes of proteinuria (urinary tract infection, heart failure, acute febrile illness, hematuria or excessive physical activity). DKD was defined as the presence of albuminuria in connection with a 10-or-more-year history of diabetes or with diagnosed diabetic retinopathy (KDOQI 2007). ${ }^{14}$

Neuropathy assessment was performed using pressure sensation (10 g monofilament perception), vibration perception (a $128 \mathrm{~Hz}$ tuning fork) and ankle reflex tests. Diabetic neuropathy was diagnosed in patients with 2 or more of the 4 following: the presence of typical symptoms of neuropathy, the absence of ankle tendon reflexes, and/or abnormal scores for pressure and/or vibration perception.

Microangiopathy was defined as the presence of at least 1 of the following microvascular complications: retinopathy, DKD or neuropathy. Macroangiopathy was defined as the presence of either coronary heart disease, a known episode of myocardial infarction, stroke or the presence of peripheral artery disease.

\section{Statistical analysis}

The statistical analysis was run using STATISTICA v. 8.0 software (StatSoft, Tulsa, USA). To test for normality, the Kolmogorov-Smirnov test with the Lilliefors correction was used. The results for continuous variables are shown as median values and IQR, and for categorical data the results are shown as numbers and percentages of patients. To compare subgroups, the Mann-Whitney U test was performed. To compare qualitative data, the $X^{2}$ test was used. The Spearman rank correlation method was used to test relationships between OPG and other variables. To determine factors connected with diabetic microangiopathy, univariate logistic regression was used. P-values $<0.05$ were considered statistically significant.

\section{Results}

Retinopathy was diagnosed in 28 patients (38\%), DKD in 28 patients (38\%), and neuropathy in 17 patients $(23 \%)$ (Fig. 1). Macroangiopathy was diagnosed in 3 cases (4\%). 
The median HbA1c level was 7.7\% (7.1-8.7). The median OPG level was $43.8 \mathrm{pg} / \mathrm{mL}$ (28.0-74.0).

With regard to the metabolic control assessment in relation to the presence of microvascular complications, the only positive finding was higher triglyceride levels in patients with retinopathy $(\mathrm{p}=0.002)$, DKD $(\mathrm{p}=0.02)$, and when any microangiopathy was considered $(\mathrm{p}=0.04)$ than in patients without these complications. Significantly higher HbA1c levels were found in patients with retinopathy ( $\mathrm{p}<0.001)$, DKD ( $<<0.001)$, and neuropathy $(\mathrm{p}=0.01)$ than in patients without these complications (Table 2).

Higher OPG levels were observed in patients with diabetic retinopathy, DKD, peripheral neuropathy, and when any microangiopathy was considered, as compared to subjects without vascular complications (Table 2). However, the results were statistically significant only in relation to retinopathy $(47.5 \mathrm{pg} / \mathrm{mL}[35.0-87.8]$ vs $35.4 \mathrm{pg} / \mathrm{mL}$ [24.7-69.4]; $\mathrm{p}=0.04$ ) (Fig. 2).

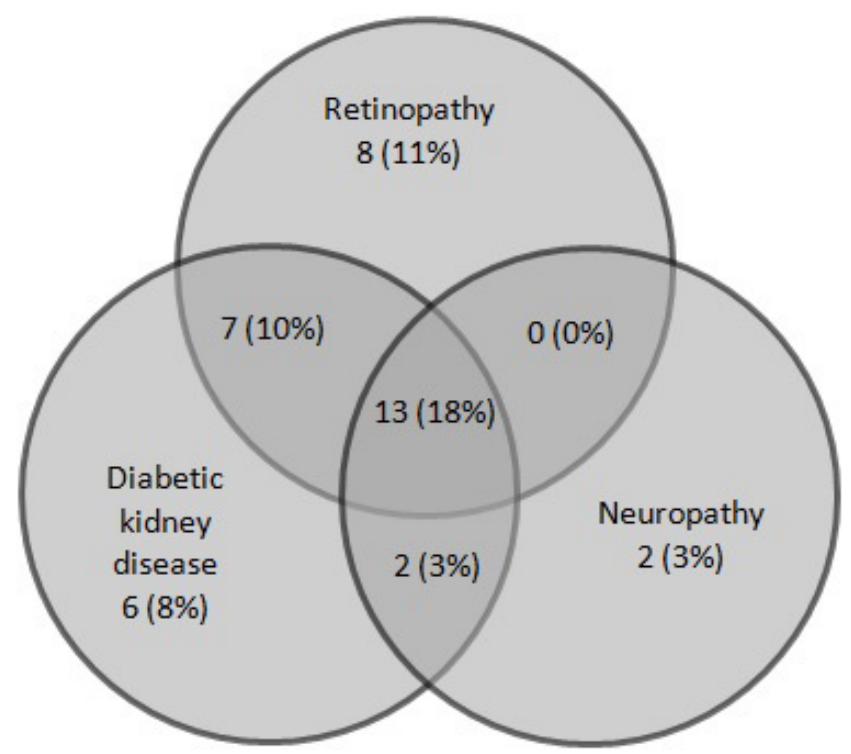

Fig. 1. Microangiopathic complications in the study group

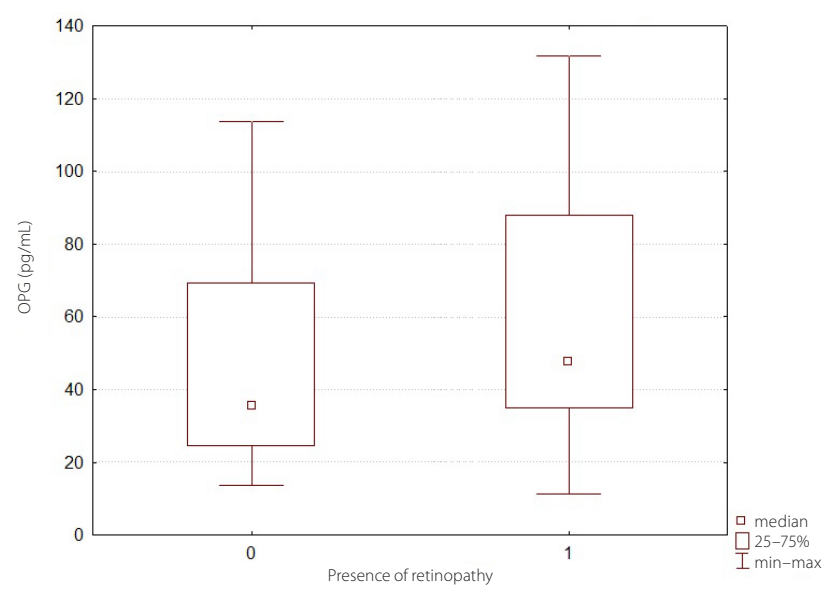

Fig. 2. OPG concentration in relation to the presence of retinopathy
In the univariate logistic regression, OPG levels were significantly associated with retinopathy (OR 1.02, 95\% CI 1.01-1.04; $\mathrm{p}=0.03)$. Positive correlations were found between OPG concentration and hsCRP ( $\mathrm{Rs}=0.53$; $\mathrm{p}<0.001)$, HbA1c level ( $\mathrm{ss}=0.36 ; \mathrm{p}=0.002)$, VAI $(\mathrm{Rs}=0.23 ; \mathrm{p}=0.04)$ and waist circumference $(\mathrm{Rs}=0.24$; $\mathrm{p}=0.04)$.

\section{Discussion}

OPG is a bone-related peptide that can be found in different tissues, including bone, heart, and vascular endothelial cells. ${ }^{11}$ Hofbauer and Schoppet wrote that endothelial cells activated by pro-inflammatory cytokines might be a potential source of circulating OPG. ${ }^{15}$ This mechanism could explain the link between low-grade inflammation and elevated OPG levels in patients with DM 2 and DM 1. ${ }^{16,17}$ Recent studies have shown elevated serum OPG concentrations in patients with microangiopathic diabetes complications. ${ }^{9,11,18,19}$ Endothelial dysfunction and vascular damage is regarded as possibly being the linking pathway between vascular complications and higher OPG levels. ${ }^{10}$ There are few studies exploring the role of OPG in the pathogenesis of microangiopathy in DM 1 patients. In the Finnish Diabetic Nephropathy Study, the authors speculate on the possible role of inflammation in the increased expression of OPG. ${ }^{9}$ However, there is no literature concerning this issue among patients treated with IFIT from the onset of the disease.

The present study showed that, among the microangiopathic complications under consideration, it was only in diabetic retinopathy that the OPG concentration was significantly higher than in patients without retinopathy. To the authors' knowledge, this is the first study showing this correlation in patients with DM 1. Yu et al. showed elevated serum and vitreous concentrations of OPG in patients with DM 2 with retinopathy. ${ }^{18}$ In another study of patients with DM 2, the authors revealed a positive association between an OPG gene polymorphism and diabetic retinopathy. ${ }^{20}$ Therefore, the role of OPG in diabetic complications might be partially explained by genetic factors.

Furthermore, strong associations between OPG, DKD and neuropathy have been described, 9,11 The lack of statistical significance in the results of the present study might be explained by the whole study group having quite good metabolic control of their diabetes. However, in the subgroups with complications, significantly higher levels of HbA1c were observed. Hyperglycemia and the associated activation of inflammatory process appear to be the main mechanisms leading to the production of OPG. The HbA1c values presented were measured during the patients' final follow-up, and were remarkably lower than described in papers by Gordin et al. and Knudsen et al., who did not describe the treatment method., ${ }^{9,10}$ The patients in the PoProStu group have been treated 


\begin{tabular}{|c|c|c|c|c|c|c|c|c|c|c|c|c|c|c|c|c|c|c|c|}
\hline $\begin{array}{l}\overline{3} \\
\bar{a}\end{array}$ & 1 & $气$ & $\check{E}$ & 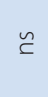 & ठ̊. & రి. & 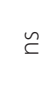 & 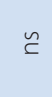 & 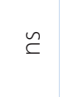 & $\check{\complement}$ & 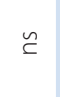 & 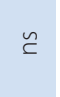 & so. & $气$ & 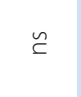 & 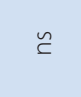 & $\begin{array}{l}\text { ¿ } \\
0\end{array}$ & 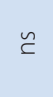 & $\frac{\infty}{0}$ \\
\hline 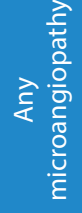 & $\stackrel{\infty}{m}$ & $\underset{\sim}{\stackrel{\circ}{\infty}}$ & 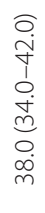 & 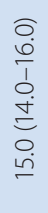 & 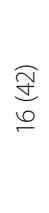 & 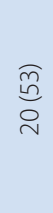 & 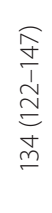 & 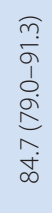 & 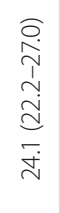 & 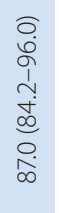 & 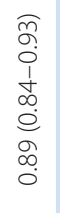 & 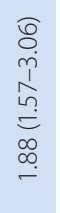 & 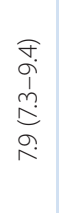 & 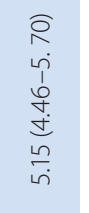 & 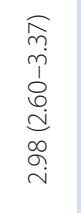 & 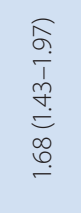 & 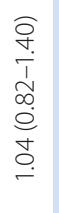 & $\begin{array}{l}\widehat{\bar{o}} \\
\stackrel{1}{1} \\
\infty \\
\infty \\
\stackrel{0}{n} \\
m \\
\end{array}$ & 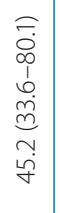 \\
\hline 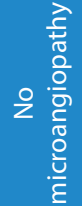 & $\stackrel{\infty}{m}$ & $\stackrel{\infty}{\grave{N}}$ & 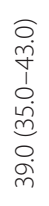 & 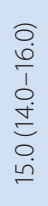 & $\underbrace{E}_{0}$ & 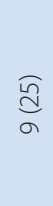 & 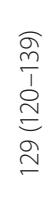 & 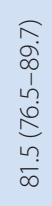 & 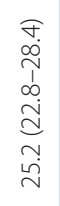 & 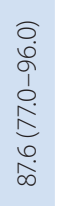 & 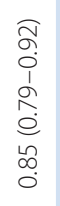 & $\begin{array}{l}\widehat{\widehat{o}} \\
\stackrel{j}{j} \\
\stackrel{0}{\rho} \\
\stackrel{\rho}{\infty} \\
\stackrel{0}{\rightleftharpoons}\end{array}$ & $\begin{array}{l}\text { a } \\
o \\
0 \\
o \\
\dot{0} \\
m \\
\end{array}$ & 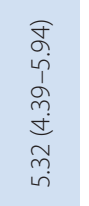 & 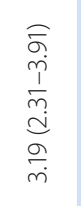 & 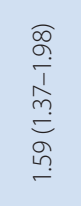 & 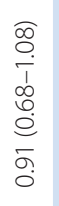 & 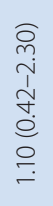 & $\begin{array}{l}\vec{\sigma} \\
\stackrel{n}{1} \\
\hat{n} \\
\stackrel{d}{0} \\
\sim \\
\tilde{m} \\
m\end{array}$ \\
\hline & 1 & ठ̊. & $\tilde{\varepsilon}$ & $\tilde{\varepsilon}$ & 苂 & $\begin{array}{l}\bar{o} \\
\stackrel{\circ}{\circ}\end{array}$ & $气$ & $气$ & 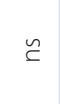 & $\tilde{\complement}$ & $\simeq$ & 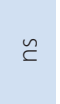 & $\bar{\sigma}_{0}$ & $\tilde{\varepsilon}$ & $\check{\varepsilon}$ & $\tilde{c}$ & $\tilde{c}$ & $\tilde{c}$ & $\stackrel{n}{n}$ \\
\hline 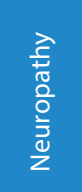 & $=$ & $\stackrel{2}{\check{n}}$ & 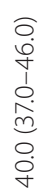 & 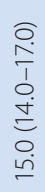 & $\begin{array}{l}\text { 鬲 } \\
0\end{array}$ & $\underset{n}{E}$ & 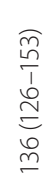 & $\begin{array}{l}\widehat{\alpha} \\
\hat{d} \\
\alpha \\
\Omega \\
\infty \\
\infty\end{array}$ & 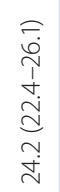 & $\begin{array}{l}\widehat{\widehat{N}} \\
\hat{1} \\
\omega \\
\infty \\
\infty \\
\infty\end{array}$ & 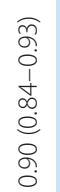 & 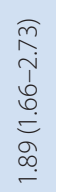 & 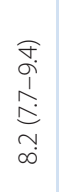 & 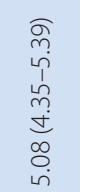 & 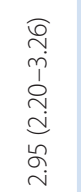 & 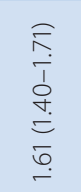 & 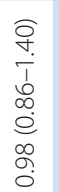 & 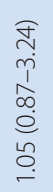 & 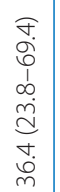 \\
\hline 气 & in & 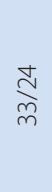 & 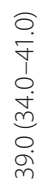 & 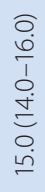 & $\underset{\simeq}{\stackrel{\bar{d}}{\simeq}}$ & 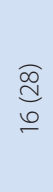 & 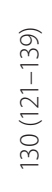 & 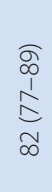 & 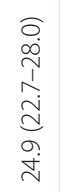 & $\begin{array}{l}\bar{\infty} \\
\frac{1}{\infty} \\
\infty \\
\infty\end{array}$ & $\begin{array}{l}\widehat{\Omega} \\
0 \\
1 \\
0 \\
0 \\
0 \\
0 \\
0 \\
0 \\
0\end{array}$ & 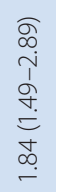 & $\begin{array}{l}\sqrt{n} \\
0 \\
0 \\
o \\
0 \\
0 \\
\vdots \\
N\end{array}$ & 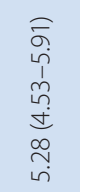 & 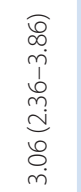 & 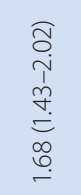 & 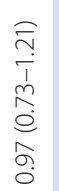 & 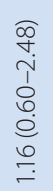 & 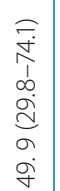 \\
\hline & I & 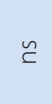 & 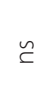 & 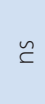 & $\begin{array}{l}\bar{\partial} \\
\dot{0} \\
\dot{v}\end{array}$ & $\begin{array}{l}\bar{\delta} \\
\text { ¿े. } \\
\text { v }\end{array}$ & ơ & 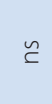 & 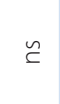 & $\stackrel{m}{0}$ & 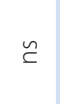 & $\check{\simeq}$ & $\begin{array}{l}\bar{\partial} \\
\dot{Q} \\
\dot{v}\end{array}$ & 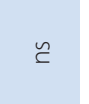 & $\tilde{c}$ & $\tilde{\complement}$ & $\stackrel{\text { O̊ }}{0}$ & 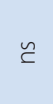 & $\stackrel{\frac{\omega n}{\circ}}{\circ}$ \\
\hline$\stackrel{\subsetneq}{\stackrel{c}{c}}$ & $\stackrel{\infty}{\sim}$ & సి & 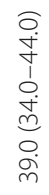 & 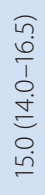 & 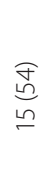 & 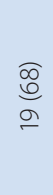 & 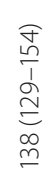 & $\begin{array}{l}\text { f } \\
\frac{1}{1} \\
\frac{1}{\infty} \\
\infty \\
\infty\end{array}$ & 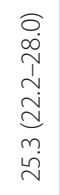 & $\begin{array}{l}\bar{\sigma} \\
\hat{1} \\
\mathbf{b} \\
\approx \\
\sigma\end{array}$ & $\begin{array}{l}\bar{\Phi} \\
\circ \\
0 \\
1 \\
\infty \\
\infty \\
0 \\
\circ \\
\circ \\
0 \\
0\end{array}$ & 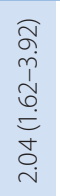 & 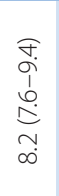 & 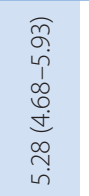 & 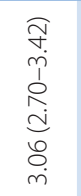 & 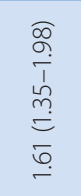 & 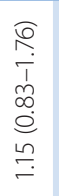 & 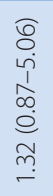 & 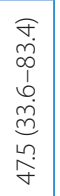 \\
\hline & \& & 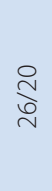 & 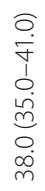 & 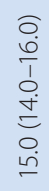 & 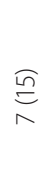 & $\begin{array}{l}\underset{\mathbb{d}}{0} \\
\stackrel{0}{1}\end{array}$ & 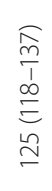 & $\begin{array}{l}\widehat{\sigma} \\
\infty \\
+ \\
\\
\bar{\infty} \\
\bar{\infty}\end{array}$ & $\begin{array}{l}\underset{d}{\mathbb{N}} \\
\stackrel{1}{d} \\
\underset{d}{N} \\
\stackrel{1}{d}\end{array}$ & 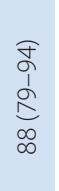 & 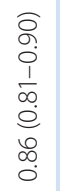 & 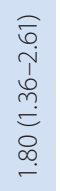 & 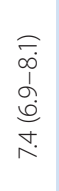 & 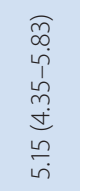 & 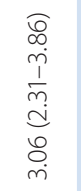 & 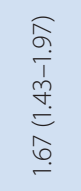 & 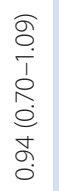 & 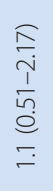 & $\begin{array}{l}\overrightarrow{0} \\
\tilde{N} \\
\hat{i} \\
0 \\
\stackrel{d}{0} \\
0 \\
\infty \\
m \\
m\end{array}$ \\
\hline 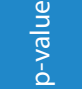 & 1 & 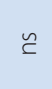 & $\check{\varepsilon}$ & $\check{\varepsilon}$ & $\bar{\delta}_{0}$ & ஜ̊ & $\tilde{c}$ & ¿. & $气$ & $\check{c}$ & 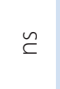 & 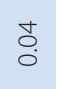 & $\begin{array}{l}\bar{o} \\
\dot{0} \\
\dot{v}\end{array}$ & $\tilde{\varepsilon}$ & $\tilde{c}$ & $\tilde{\complement}$ & ठ̊. & 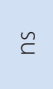 & $\begin{array}{l}\dot{D} \\
\dot{0}\end{array}$ \\
\hline 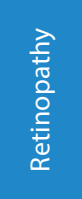 & $\stackrel{\infty}{\sim}$ & $\underset{\text { సొ }}{ }$ & 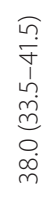 & 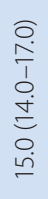 & $\frac{\substack{o \\
m}}{m}$ & $\underset{\stackrel{\sigma}{a}}{\stackrel{a}{\imath}}$ & 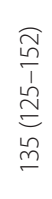 & $\begin{array}{l}\widehat{\widetilde{m}} \\
\frac{1}{\infty} \\
\stackrel{\infty}{\infty}\end{array}$ & 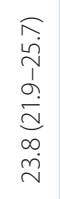 & $\begin{array}{l}\bar{\infty} \\
\phi \\
\infty \\
\infty \\
\infty \\
\infty\end{array}$ & 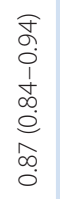 & 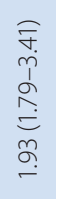 & \begin{tabular}{l}
$\sqrt[n]{n}$ \\
$\hat{1}$ \\
$\hat{N}$ \\
\multirow{N}{*}{} \\
$\infty$ \\
$\infty$
\end{tabular} & 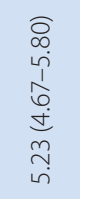 & 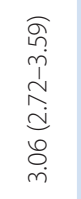 & 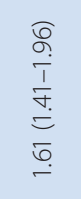 & 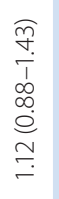 & 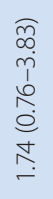 & 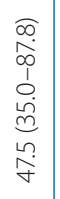 \\
\hline 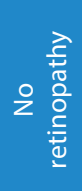 & of & 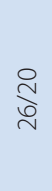 & 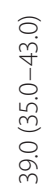 & 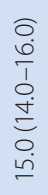 & $\begin{array}{l}\text { d্d } \\
\text { a }\end{array}$ & 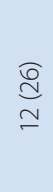 & 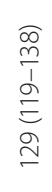 & $\begin{array}{l}\widehat{\Phi} \\
\vdots \\
+ \\
\\
\infty\end{array}$ & 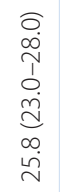 & $\begin{array}{l}\bar{\infty} \\
\frac{1}{\infty} \\
\infty \\
\infty \\
\infty\end{array}$ & $\begin{array}{l}\widehat{\alpha} \\
0 \\
\frac{1}{\infty} \\
0 \\
0 \\
0 \\
\infty \\
0 \\
0\end{array}$ & 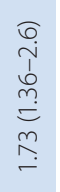 & $\begin{array}{l}\widehat{\sigma} \\
\hat{n} \\
\infty \\
\stackrel{0}{0} \\
m \\
\end{array}$ & 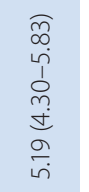 & 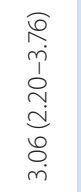 & 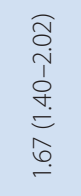 & 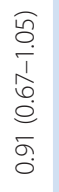 & 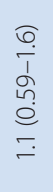 & 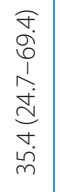 \\
\hline 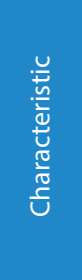 & & 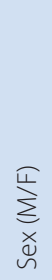 & 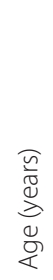 & 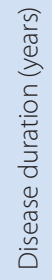 & 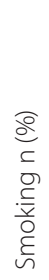 & 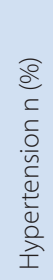 & $\begin{array}{l}\text { ô } \\
\stackrel{\text { Tे }}{\varepsilon} \\
\underline{\xi}\end{array}$ & 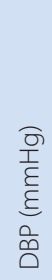 & 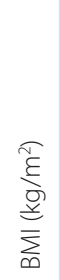 & 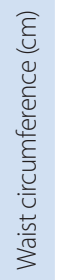 & $\stackrel{\frac{c}{1}}{\vec{z}}$ & $\bar{s}$ & 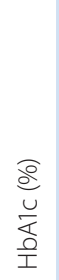 & 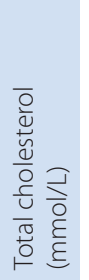 & 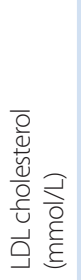 & 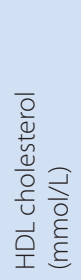 & 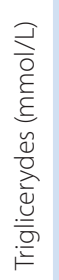 & 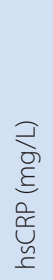 & 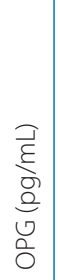 \\
\hline
\end{tabular}


from the onset of the disease with IFIT, ensuring better metabolic control and thus a reduction in the prevalence of complications. $^{21}$

The current study group's relatively short history of diabetes might be another reason for the relatively low OPG levels found. Higher concentrations of OPG might occur in the more advanced stages of microvascular complications. In studies by Gordin et al. and Nybo et al., a significantly longer history of diabetes results in greater prevalence of microangiopathy. ${ }^{9,11}$ Finally, significantly elevated OPG levels were described in the presence of macroangiopathy by Doherty et al. ${ }^{3}$ The limited cases of macroangiopathic complications in the present study, even when microangiopathy was diagnosed, might have resulted in the relatively low OPG concentration as compared to the data in the literature.

Low-grade inflammation has been associated with macro- and microvascular complications in DM 1 subjects. ${ }^{22}$ Serum hsCRP concentration has been directly proven to be a strong predictor of microangiopathic complications in diabetes. ${ }^{23-25}$ It is also a well-known marker for the inflammation response. Yaturu et al. found correlations between OPG and insulin resistance, CRP, TNFalpha concentrations, and showed elevated OPG in diabetic patients compared to control subjects. ${ }^{26}$ The present study found a positive correlation between concentrations of OPG and hsCRP. Pro-inflammatory cytokines might promote OPG production by endothelial cells and thus cause intensification of the calcification process and vascular damage. Recently, it has been shown that OPG expression can be induced by glucose and insulin, and OPG itself increases the production of IL- 6 and IL-8. ${ }^{27}$ This finding confirms the fact that OPG is involved in the pathogenesis of both endothelial dysfunction and inflammation. Hyperglycemia contributes to the activation of inflammatory processes and to the pathogenesis of complications. The present study found a positive correlation between OPG and HbA1c levels. Similar results were observed by Knudsen et al. ${ }^{10}$ As in previously published data, the present study showed a positive correlation between OPG and insulin resistance, assessed using the visceral adiposity index and waist circumference. ${ }^{28}$ Plasma concentrations of hsCRP are elevated in insulin resistant patients in the work by Festa et al. and Ndumele et al. ${ }^{24,29}$ Low-grade inflammation might be regarded as an underlying pathogenetic mechanism for the relationship between OPG and IR. Additionally, considering the confirmed relationship between IR and cardiovascular disease, this finding supports the growing concept that OPG might be used as a serum biomarker identifying patients at risk for adverse outcomes. ${ }^{30}$ The correlations described above could also support the idea that upregulation of OPG might be explained by pathways altered by IR and low-grade inflammation.

Some limitations of the present study should be mentioned. Firstly, the study group is relatively small. Further investigations of a larger cohort of type 1 diabetes patients in the Poznań Clinical Database of Diabetes are planned. Secondly, there was considerable variability in the participants' OPG measurements, which might have influenced the results. Finally, retinopathy was evaluated by a single ophthalmologist, which leaves the potential for a diagnostic bias. However, every patient had fundus photographs taken to support the ophthalmologist's assessment.

In conclusion, higher concentrations of OPG in DM 1 patients might be related to the presence of retinopathy. The study results indicate that OPG may play a role in the pathogenesis of diabetic retinopathy in association with hyperglycemia and low-grade inflammatory processes.

\section{References}

1. Simonet WS, Lacey DL, Dunstan CR, et al. Osteoprotegerin: A novel secreted protein involved in the regulation of bone density. Cell. 1997;89:309-319.

2. Schoppet M. RANK ligand and osteoprotegerin: Paracrine regulators of bone metabolism and vascular function. Arterioscler Thromb Vasc. Biol 2002;22:549-553.

3. Doherty TM, Fitzpatrick LA, Inoue D, et al. Molecular, endocrine, and genetic mechanisms of arterial calcification. Endocr Rev. 2004;25:629-672.

4. Bjerre M, Hilden J, Kastrup J, et al. Osteoprotegerin independently predicts mortality in patients with stable coronary artery disease: The CLARICOR trial. Scand J Clin Lab Invest. 2014;74:657-664.

5. Suliburska J, Bogdanski P, Gajewska E, Kalmus G, Sobieska M, Samborski W. The association of insulin resistance with serum osteoprotegerin in obese adolescents. J Physiol Biochem. 2013;69:847-853.

6. Bjerre M. Osteoprotegerin (OPG) as a biomarker for diabetic cardiovascular complications. SpringerPlus. 2013;2:658.

7. Lopes-Virella MF, Carter RE, Gilbert GE, et al. Risk factors related to inflammation and endothelial dysfunction in the DCCT/EDIC cohort and their relationship with nephropathy and macrovascular complications. Diabetes Care. 2008;31:2006-2012.

8. Astrup AS, Tarnow L, Pietraszek L, et al. Markers of endothelial dysfunction and inflammation in type 1 diabetic patients with or without diabetic nephropathy followed for 10 years: Association with mortality and decline of glomerular filtration rate. Diabetes Care. 2008;31:1170-1176.

9. Gordin D, Soro-Paavonen A, Thomas MC, et al. Osteoprotegerin is an independent predictor of vascular events in Finnish adults with type 1 diabetes. Diabetes care. 2013;36:1827-1833.

10. Knudsen ST, Foss CH, Poulsen PL, Andersen NH, Mogensen CE, Rasmussen LM. Increased plasma concentrations of osteoprotegerin in type 2 diabetic patients with microvascular complications. Eur J Endocrinol. 2003;149:39-42.

11. Nybo M, Poulsen MK, Grauslund J, Henriksen JE, Rasmussen LM. Plasma osteoprotegerin concentrations in peripheral sensory neuropathy in type 1 and type 2 diabetic patients. Diabet Med. 2010;27:289-294.

12. Grzelka A, Araszkiewicz A, Uruska A, Zozulińska-Ziółkiewicz D. Prevalence of anti-thyroid peroxidase in adults with type 1 diabetes participating in Poznań Prospective Study. Adv Clin Exp Med. 2015;24:79-84.

13. Wilkinson C, Ferris FL, Klein RE, et al. Proposed international clinical diabetic retinopathy and diabetic macular edema disease severity scales. Ophthalmology. 2003;110:1677-1682.

14. KDOQI. KDOQI clinical practice guidelines and clinical practice recommendations for diabetes and chronic kidney disease. Am J Kidney Dis. 2007:49:12-154.

15. Hofbauer LC. Clinical implications of the osteoprotegerin/RANKL/ RANK system for bone and vascular diseases. JAMA. 2004;292:490.

16. Xiang GD, Xu L, Zhao LS, Yue L, Hou J. The relationship between plasma osteoprotegerin and endothelium-dependent arterial dilation in type 2 diabetes. Diabetes. 2006;55:2126-2131. 
17. Xiang G, Sun H, Zhao L. Changes of osteoprotegerin before and after insulin therapy in type 1 diabetic patients. Diabetes Res Clin Pract. 2007:76:199-206.

18. Yu G, Ji X, Jin J, Bu S. Association of serum and vitreous concentrations of osteoprotegerin with diabetic retinopathy. Ann Clin Biochem Int J Biochem Lab Med. 2015;52:232-236.

19. Wang S, Xu J, Wang M, Chen F, Ding G. Increased plasma osteoprotegerin concentrations in type 1 diabetes with albuminuria. Clin Nephrol. 2013;79:192-198.

20. Mankoč Ramuš $S$, Kumše $T$, Globočnik Petrovič $M$, Petrovič $D$, Cilenšek I. SNP rs2073618 of the osteoprotegerin gene is associated with diabetic retinopathy in Slovenian patients with type 2 diabetes. BioMed Res Int. 2013;2013:1-6.

21. Diabetes Control and Complications Trial Research Group. Nathan DM, Genuth $S$, et al. The effect of intensive treatment of diabetes on the development and progression of long-term complications in insulin-dependent diabetes mellitus. NEnglJ Med. 1993;329:977-986.

22. Schram MT, Chaturvedi N, Schalkwijk CG, Fuller JH, Stehouwer CDA; EURODIAB Prospective Complications Study Group. Markers of inflammation are cross-sectionally associated with microvascular complications and cardiovascular disease in type 1 diabetes The EURODIAB Prospective Complications Study. Diabetologia. 2005:48:370-378.

23. Saraheimo M, Teppo AM, Forsblom C, Fagerudd J, Groop PH. Diabetic nephropathy is associated with low-grade inflammation in type 1 diabetic patients. Diabetologia. 2003;46:1402-1407.

24. Festa A, D'agostino R, Howard G, Mykkänen L, Tracy RP, Haffner SM. Inflammation and microalbuminuria in nondiabetic and type 2 diabetic subjects: The Insulin Resistance Atherosclerosis Study. Kidney Int. 2000;58:1703-1710.

25. Navarro JF, Mora C, Maciéa M, Garciéa J. Inflammatory parameters are independently associated with urinary albumin in type 2 diabetes mellitus. Am J Kidney Dis. 2003;42:53-61.

26. Yaturu S, Rains J, Jain SK. Relationship of elevated osteoprotegerin with insulin resistance, CRP, and TNF-a levels in men with type 2 diabetes. Cytokine. 2008;44:168-171.

27. de Ciriza CP, Lawrie A, Varo N. OPG expression on endothelial cells and modulation by IL-1B, PDGF, insulin, and glucose. Biochem Physiol Open Access. 2015;4(4):179.

28. Llaurado G, Ceperuelo-Mallafre V, Vilardell C, et al. Arterial stiffness is increased in patients with type 1 diabetes without cardiovascular disease: A potential role of low-grade inflammation. Diabetes Care. 2012;35:1083-1089.

29. Ndumele $C E$, Pradhan $A D$, Ridker PM. Interrelationships between inflammation, C-reactive protein, and insulin resistance. J Cardiometab Syndr. 2006;1:107-196.

30. Jeppesen J, Hansen TW, Rasmussen S, Ibsen H, Torp-Pedersen C, Madsbad S. Insulin resistance, the metabolic syndrome, and risk of incident cardiovascular disease: A population-based study. J Am Coll Cardiol. 2007;49:2112-2119. 